\title{
FLOW FIELD AND SCOURING EFFECTS OF STEADY AND PULSATING JETS IMPINGING ON A MOVABLE BED
}

\author{
ETUDE DU CHAMP D'ECOULEMENT ET DES PHENOMENES D'AFFOUILLEMENT \\ DES JETS CONTINUS ET PULSES A L'IMPACT SUR UN FOND MOBILE
}

\author{
by \\ H. Kobus, P. Leister and B. Westrich \\ Institut für Wasserbau, Universität Stuttgart, Stuttgart, Federal Republic of Germany
}

\begin{abstract}
Summary The flow field and erosion pattern of continuous and pulsating impinging jets has been studied experimentally. The mean velocity field as well as turbulent and pulsation components, wall pressure and wall shear stress distributions were investigated in an axisymmetric air jet impinging upon a rough wall. The results show how harmonic velocity pulsations at the nozzle affect both the mean and the turbulent flow field. Corresponding erosion tests with a vertical water jet impinging upon a uniform sand bed exhibited under certain conditions a greatly enhanced erosion rate. The increase in erosion capacity due to pulsation seems to be due to both the changes in the mean flow field and to the greatly increased lateral correlation of the velocity field in the impinging region.
\end{abstract}

Résumé Etude expérimentale des champs d'écoulement et des schémas d'érosion correspondant à l'impact des jets continus et pulsés, portant sur la détermination de la répartition des vitesses moyennes, ainsi que des composantes turbulentes et pulsatoires de celle-ci, et des répartitions des pressions et des contraintes de cisaillement pariétales, à l'impact d'un jet d'air axisymétrique sur une paroi rugueuse. Les résultats de l'étude font ressortir l'influence des pulsations de vitesse harmoniques, présentes à la sortie de la buse, sur les caractéristiques des champs d'écoulement moyen et turbulent. Des essais correspondants, exécutés avec un jet d'eau vertical retombant sur un fond de sable uniforme, ont mis en évidence, dans certaines conditions, une très sensible intensification des phénomènes d'érosion. L'accroissement du pouvoir érosif du fait des pulsations du jet semble découler, à la fois des variations du champ d'écoulement moyen, et d'une très sensible augmentation de la corrélation latérale du champ des vitesses à l'intérieur de la zone d'impact du jet.

\section{Introduction}

Jets impinging on a movable bed of particles can lead to strong local scouring effects. Submerged jets, which in practice frequently show periodic velocity fluctuations, can either lead to dangerous scouring near hydraulic structures, or be put to technical use due to their strong erosion capacity. Unwanted effects are found, for example, in the erosion of the bottom of navigable waterways by ship propellers, whereas in dredging high velocity jets are successfully used for loosening hardpacked sandy soils, or also for submarine underground-laying of pipes. Furthermore, the flow field of impinging jets is of interest for hovercrafts and for vertical takeoffs, and also for numerous applications in chemical engineering.

In order to control the scouring effects of impinging jets, it is necessary to know in detail both the flow field and the scouring effect of this flow configuration. Therefore, an experimental

Received July 19, 1977 and revised December 22, 1978 
investigation of an axi-symmetrical, vertical, submerged jet impinging on a horizontal sand bed of uniform grain size was conducted. Particular attention was paid to the quantification of the influence of a pulsation of the jet velocity, which under certain geometrical and flow conditions causes an increase of the scouring rates.

The flow configuration investigated, as it exists at the beginning of the erosion process, is sketched in Fig. 1. For reasons of experimental techniques, this configuration was studied both in an air- and in a water model: whereas the flow field can be measured more easily in air by means of hot-wire techniques, it is more realistic to investigate the erosion process in water, where the same density ratio can be achieved as in the prototype. Therefore, the following complementary experiments were conducted:

- in the air model, the flow field of a vertical turbulent jet impinging on a horizontal rough and unerodible wall was investigated. This configuration corresponds to the initial phase of the erosion process. Preference was given to the flat plate configuration instead of a fully developed scouring hole, because the former corresponds to a simpler case, for which literature data for smooth walls are available for comparison.

- In the corresponding water model, the erosion process of a sand bed of uniform grain size due to a turbulent submerged jet was quantitatively evaluated for the same geometrical initial conditions (horizontal bed) and for various grain sizes of the sand.

The flow field and the (time-dependent) erosion process is characterized by the jet parameters (momentum flux $M_{0}$ and distance $l_{0}$ from the bed) on the one hand and the parameters of the bed material (representative grain diameter $d_{s}$ or equivalent sand roughness $k_{s}$ and fall velocity $w$ ) on the other. In pulsating jets, the amplitude $\alpha$ and the frequency $f$ of the pulsation must be

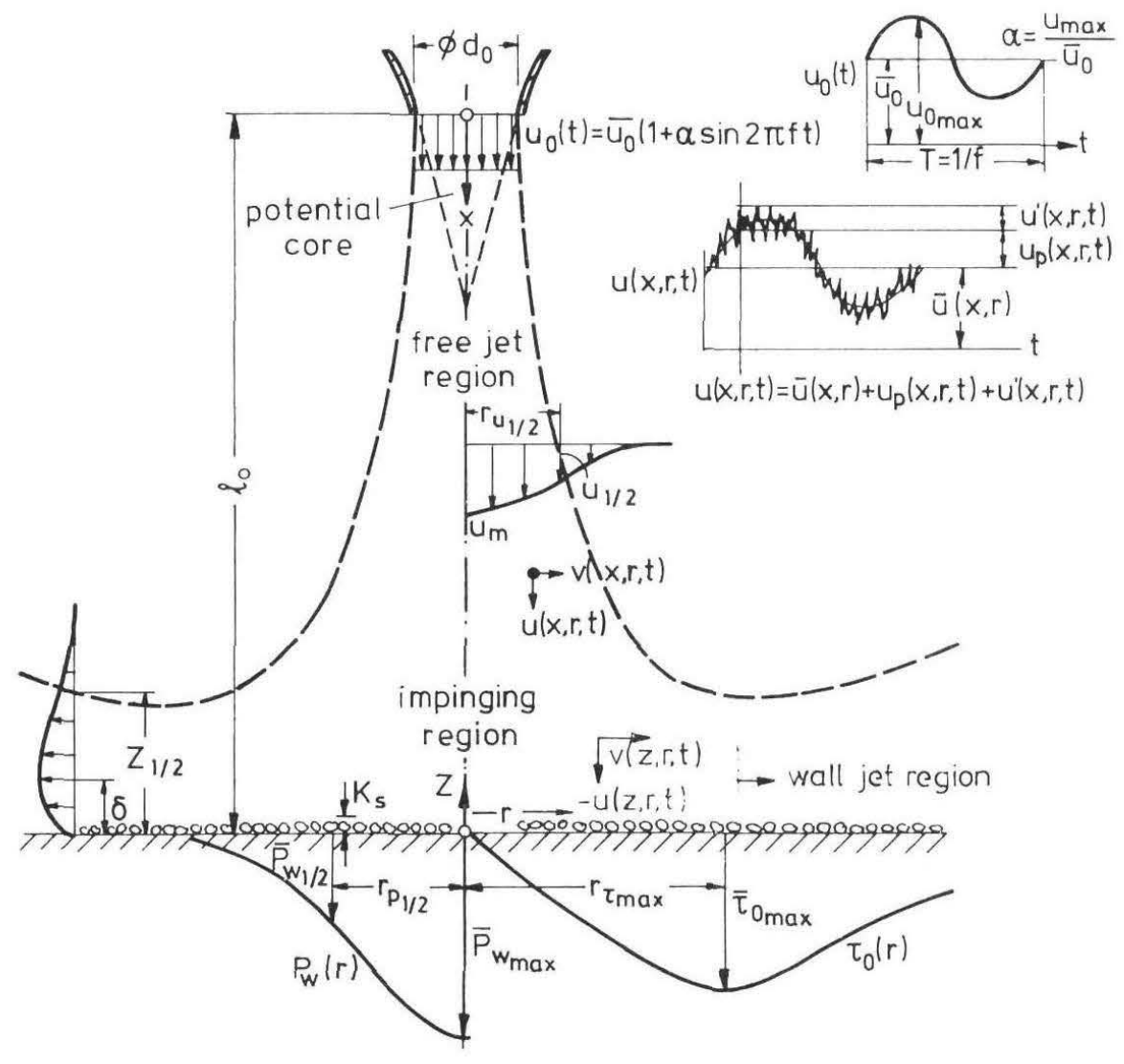

Definition sketch of an impinging jet.

Fig. 1. Croquis de définition de l'impact d'un jet. 
considered in addition. A dimensional analysis yields the following general relationship (definitions see Fig. 1):

$$
\begin{aligned}
& \text { Flow field } \\
& \text { Erosion process }
\end{aligned}=f_{1,2}\left[R e_{0} \equiv \frac{\bar{u}_{0} d_{0}}{v} ; \frac{l_{0}}{d_{0}} ; \frac{k_{s} / d_{0}}{R e_{s}} ; \frac{\bar{u}_{0}}{w} ; S r \equiv \frac{f d_{0}}{\bar{u}_{0}} ; \alpha\right]
$$

This relationship is limited to vertical, axially symmetrical turbulent jets and noncohesive bed material of uniform grain size.

For the investigations of the flow field in the fixed-bed air model, the roughness is described by the equivalent sand roughness $k_{s}$ according to Nikuradse, whereas the fall velocity $w$ is of no significance. For investigations of the flow field of impinging jets, one obtains therefore:

$$
\text { Flow field }=f_{1}\left[R e_{0} ; \frac{l_{0}}{d_{0}} ; \frac{k_{s}}{d_{0}} ; S r ; \alpha\right]
$$

Experimental range:

$$
\begin{aligned}
& R e_{0} \text { : from } 2 \cdot 10^{4} \text { to } 6 \cdot 10^{4} \text { (mainly } 6 \cdot 10^{4} \text { ) } \\
& l_{0} / d_{0}: \text { from } 11.6 \text { to } 16.6 \text { (mainly } 16.6 \text { ) } \\
& k_{s} / d_{0}: \text { from } 0 \text { to } 0.0833 \\
& S r \quad: \text { from } 0 \text { to } 6 \cdot 10^{-2} \\
& \alpha \quad \text { : from } 0 \text { to } 0.70
\end{aligned}
$$

For the erosion experiments with movable bed, fully turbulent flow can always be assumed and therefore the Reynolds number of the jet has no significance (the Reynolds numbers in the water investigations ranged from 3 to $18 \times 10^{4}$ ). In this case, one obtains

$$
\text { Erosion process }=f_{2}\left[\frac{l_{0}}{d_{0}} ; R e_{s} ; \frac{\bar{u}_{0}}{w} ; S r ; \alpha\right]
$$

Experimental range:

$$
\begin{aligned}
& l_{0} / d_{0} \text { : from } 1.6 \text { to } 41 \text { (mainly } 14.5 \text { ) } \\
& R e_{s} \text { : from } 140 \text { to } 900 \\
& \bar{u}_{0} / w \text { : from } 6.1 \text { to } 30 \\
& S r \quad: \text { from } 0.022 \text { to } 0.272 \\
& \alpha \quad \text { : from } 0 \text { to } 0.81 \text { (mainly } 0.5 \text { ) }
\end{aligned}
$$

\section{Flow field of impinging steady jets}

Impinging jets exhibit four different flow regions (Fig. 1). Immediately downstream of the nozzle, a potential core exists, which rapidly diminishes in the downstream direction due to the shear stresses. After the transition zone, a free-jet region follows, which is characterized by similarity of the velocity profiles. Near the wall, an impinging region forms, where the flow is translated from axial into radial motion, which is connected with the formation of a pressure field. The deflected flow continues as a wall jet, which contains two different shear zones: a boundary layer near the wall, in which the velocity increases from zero at the wall to the maximum value of the wall jet, and a free-shear zone, in which the jet velocity decreases again. Wall jets also show similarity profiles for the velocity distribution. 
The main parameters characterizing the flow along the wall are the wall pressure, the wall shear stress and the maximum velocity parallel to the wall. For smooth walls, both theoretical and experimental information is available in the literature for these parameters. The most important results are summarized in the papers of Glauert [1], Bradshaw and Love [2], and Poreh and Cermak [3] as well as in a more recent summary by Rajaratnam [4]. No systematic investigations are available of the influence of the wall roughness on the flow field. SANDBORN and CHAO [5] report about velocity measurements in the wall-jet region near an artificially roughened wall, whereas LAM LAU [6] and JAYATILLIKE [7] conducted such measurements on walls with sandpaper roughness. About the profiles for wall pressure and wall shear stress at a rough wall, no data are available so far.

LEISTER [8] investigated the influence of wall roughness on the distribution of wall pressure, wall shear stress and the velocity field in the wall-jet region for the parameters defined in Chapter 1. The measurements of wall pressure and wall shear stress were taken by means of a modified Preston probe, whereas for velocity measurements both a direction-sensitive Pitot probe and a constant-temperature hot-wire anemometer were used. The experimental arrangement and measurement techniques are described in detail in [8].

The measurements showed that the distribution of wall pressures is not influenced by the roughness as long as the roughness height is small in comparison to the dimensions of the deflection region. It can be shown [8] that the dimensionless wall-pressure distribution can be described with the aid of a single experimental constant to:

$$
\frac{p_{w}}{\varrho \frac{\bar{u}_{0}^{2}}{2}\left(l_{0} / d_{0}\right)^{2}}=A \exp \left[-2 A\left(r / l_{0}\right)^{2}\right] ; A=57
$$

The wall shear distribution, on the other hand, is influenced strongly by the roughness. Both in the deflection region, which shows a linear increase of the wall shear stress with radial distance, and in the wall-jet region, where the wall shear stress decays exponentially, the wall shear stress is increased with increasing wall roughness. The location of the maximum wall shear stress is shifted slightly towards the stagnation point. In Fig. 2, which shows the dimensionless wall shear distribution, the influence of the roughness parameter is clearly visible in the staggering of the experimental points. The similarity of these experimental curves indicates that the similarity behavior of the flow field is only modified by the wall roughness as compared to the field above a smooth wall.

The shear stress distributions for smooth and rough walls can be described by the following empirical relationships (with an established validity range as given by the experiments):

with

$$
\frac{\bar{\tau}_{0 \text { rough }}}{\bar{\tau}_{0 \text { smooth }}}=\left[7.43\left(\frac{k_{s}}{d_{0}}\right)^{.41} \exp \left[-7.8\left(r / l_{0}\right)+1\right]\right] R e^{.045}
$$

$$
\frac{\bar{\tau}_{0 \text { smooth }}}{\varrho \frac{\bar{u}_{0}^{2}}{2}\left(l_{0} / d_{0}\right)^{2}}=\frac{.082}{r / l_{0}}-\exp \left[-22.7\left(r / l_{0}\right)^{2}\right]\left(\frac{.082-13.4\left(r / l_{0}\right)^{2}}{r / l_{0}}\right) R e_{0}^{-.17}
$$

The effect of the wall roughness on the flow field is shown in Fig. 3. A comparison of the profiles for smooth and for rough walls indicates clearly that the velocities are decaying more rapidly 


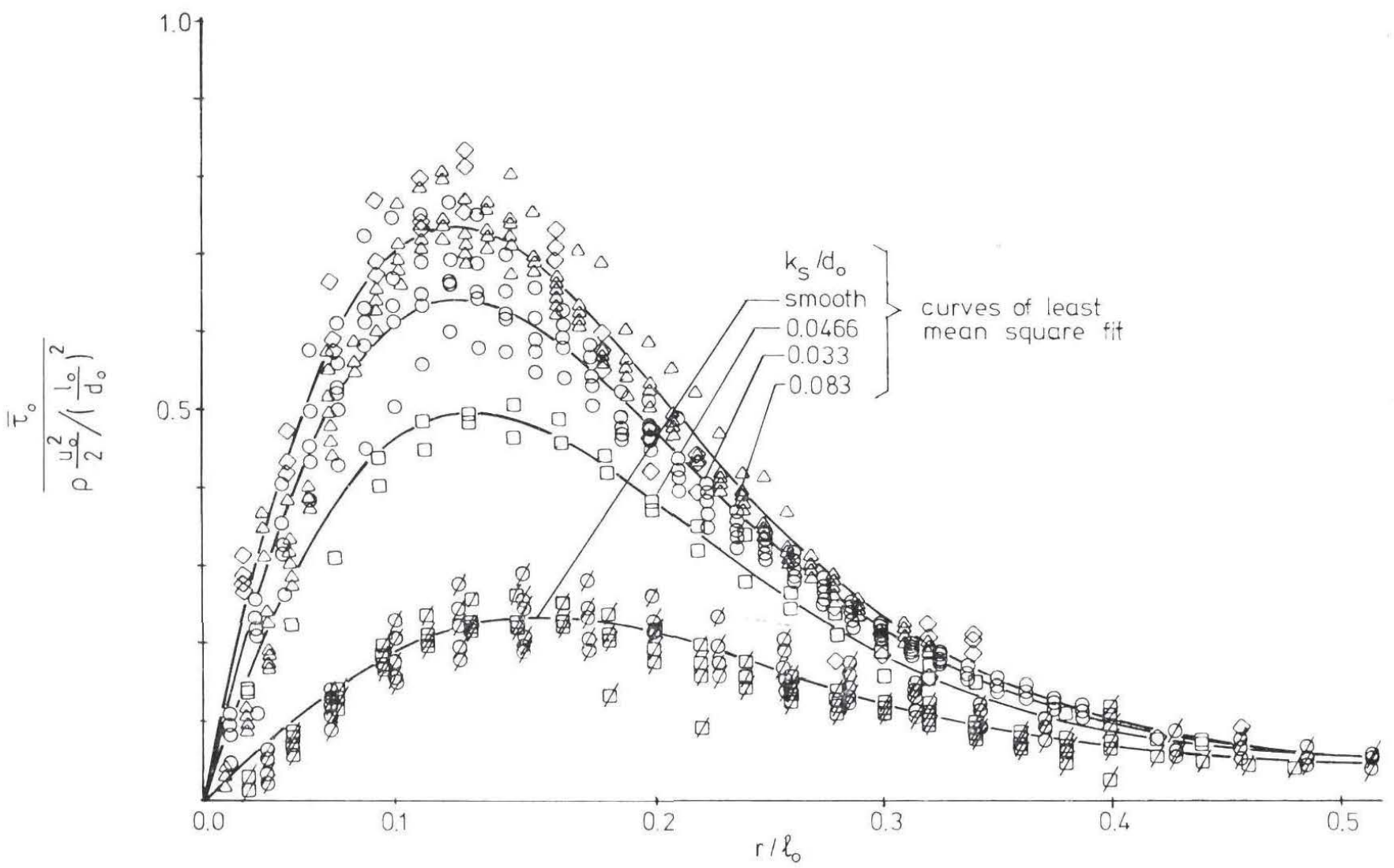

Influence of wall roughness on the wall shear stress.

Fig. 2. Influence de la rugosité de paroi sur la contrainte de cisaillement pariétale.

with distance from the stagnation point near the rough wall, which is connected with a more rapid increase of the boundary-layer thickness, characterized by the shifting of the points of maximum velocity away from the wall.

The behavior of the axial stochastic turbulence components is changed in the boundary layer by the wall roughness insofar as the intensities in the immediate vicinity of the wall are increased as compared to a smooth wall. However, the roughness has no influence on the turbulence characteristics in the free-shear zone (see Fig. 3).

\section{Scouring due to impinging steady jets}

Investigations on the erosion capacity of steady jets have been conducted by PoreH and HefEz [12], Rouse [13] and Altinbilek and Okyay [14] with vertical jets, whereas Laursen [15] and O'LoughLin and others [16] have studied the erosion capacity of weakly inclined jets and jets parallel to the bed. The laboratory investigations served primarily the purpose to establish the time dependence for local erosion problems and to aid in developing similarity criteria for scouring problems in hydraulic models. The importance of the pressure- and velocity field near the bed or the importance of the permeability of the bed for the erosion process has not yet been explored.

The time development of bed deformation can be well described by a logarithmic law. A semilogarithmic presentation of the erosion process shows two distinct phases, during each of which the eroded scouring volume is proportional to the logarithm of erosion time (Fig. 4). The erosion rate, defined as the growth rate of the scour volume, reaches a maximum immediately after 

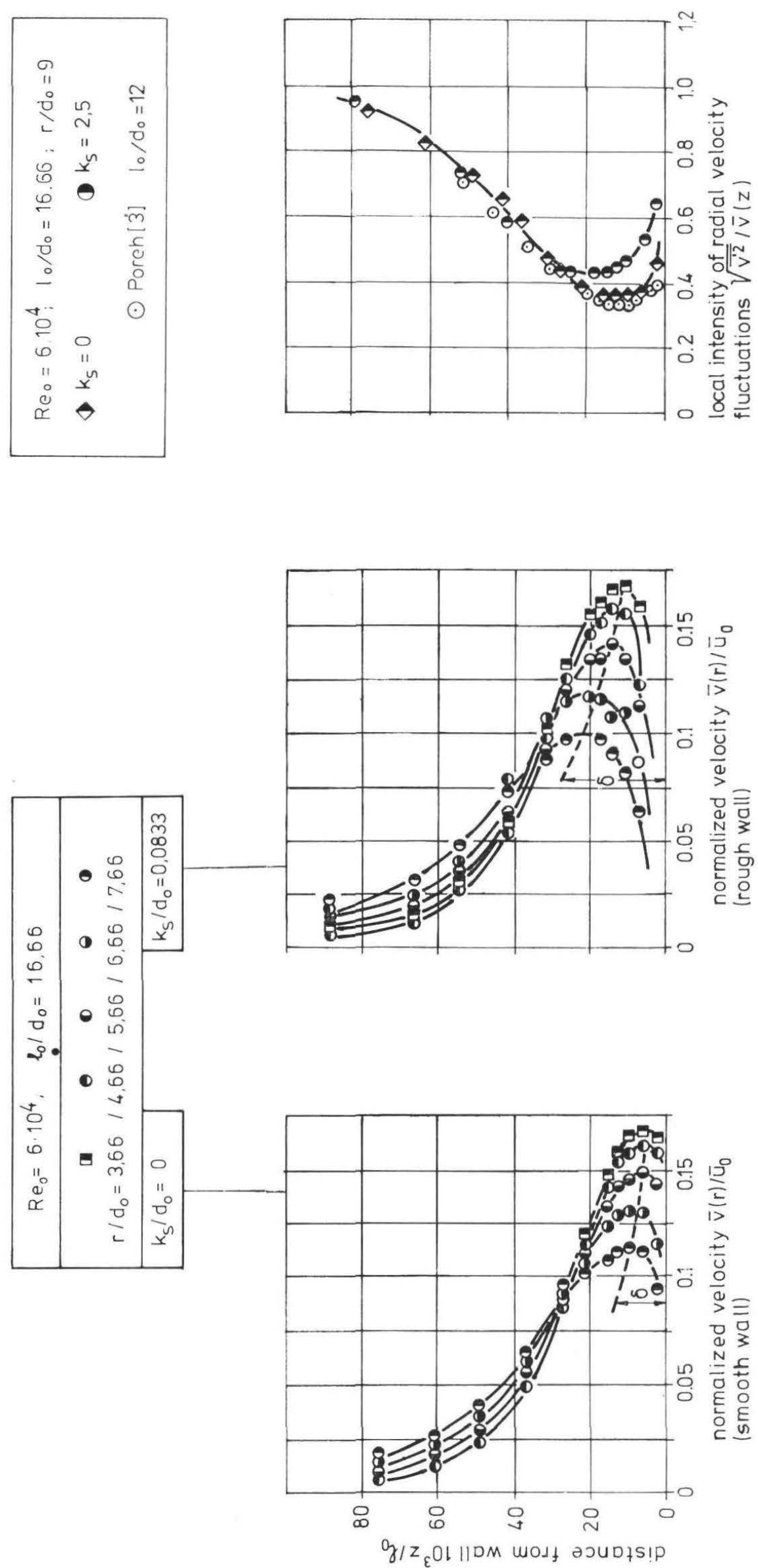

Velocity distribution in the wall jet region.

Fig. 3.

Répartition des vitesses dans la zone du jet de paroi. 


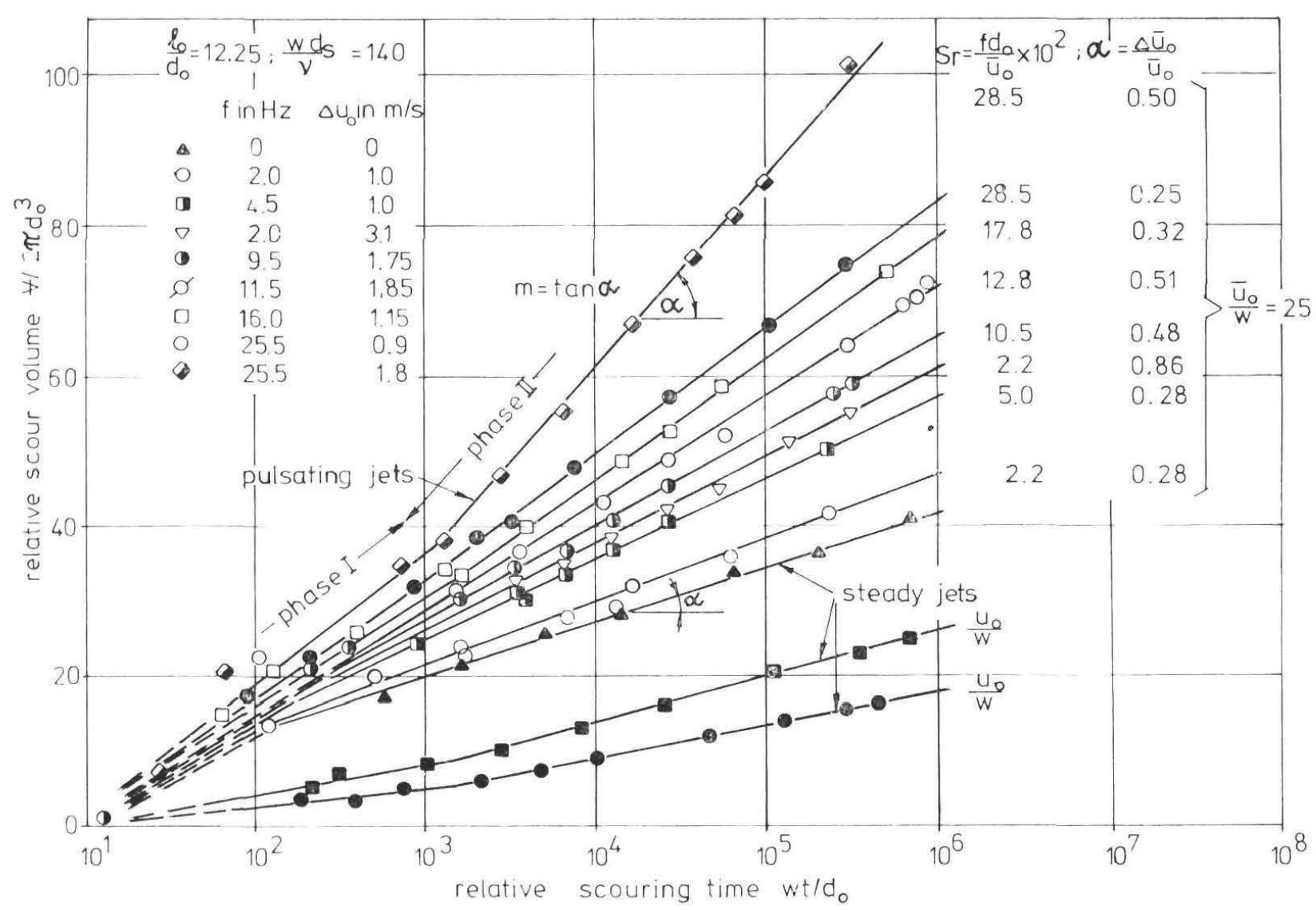

Time development of scour volume for steady

Fig. 4.

Jets continus et pulsés: évolution du volume d'affouillement dans le temps.

initiating the erosion process, when the bed is still horizontal and most of the jet energy can be translated into erosion and transport work.

For the analysis of the erosion of a sandbed by jets, the permeability and erodibility of the wall has to be considered. For an impervious bed, the stagnation pressure $p_{s}$ is proportional to the square of the fictitious centerline velocity $u_{m, l}$ of the submerged free jet at a distance $l_{0}$ from the nozzle, which in turn is proportional to the nozzle-exit velocity $u_{0}$ :

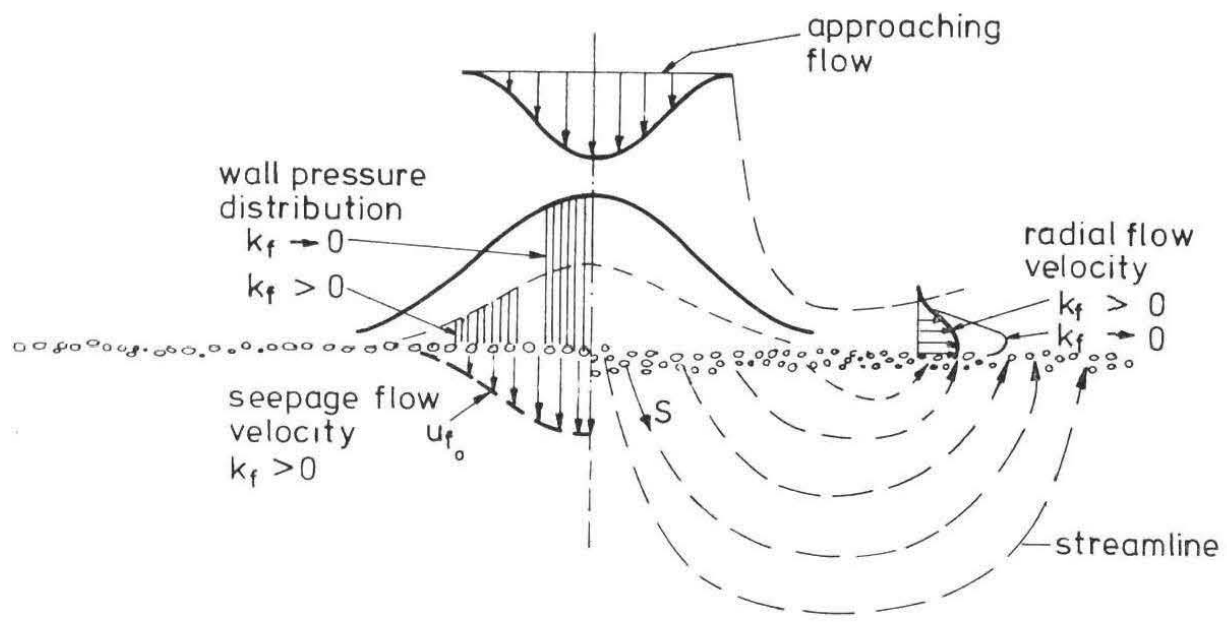

Influence of seepage flow on the pressure and velocity field at a permeable boundary.
Fig. 5. Influence de l'écoulement d'infiltration sur les répartitions des vitesses et des pressions au voisinage immédiat d'une paroi perméable. 


$$
p_{s}=p_{w}(r=0) \propto \frac{\varrho}{2} u_{m, l}^{2} \propto \frac{\varrho}{2} u_{0}^{2}
$$

For a pervious erodible bed, the magnitude of the stagnation pressure is furthermore dependent on the shape of the bed profile and the Reynolds number of the grain, which characterizes the degree of infiltration. Fig. 5 qualitatively shows the influence of the permeability of the bed material on the pressure- and velocity profile in the deflection- and wall-jet region, as compared to the situation for an impervious bed. With increasing permeability, the actual stagnation pressure is reduced and the radial velocities as well as the resulting bed shear stresses are also diminished, since not the entire longitudinal jet momentum is converted into radial momentum. The more energy is put into the seepage motion, the smaller is the remaining energy for erosion and transport of the bed material, since the seepage flow does not contribute to the hydromechanical erosion [17]. The influence of the seepage velocity increases with increasing permeability $k_{f}$ and with increasing gradient of the piezometric head in the plane of the bed:

$$
u_{f 0}=k_{f} \frac{\partial h}{\partial s} \sim k_{f} \frac{p_{s} / \varrho g}{b}
$$

where $b$ is the (fictitious) nominal width of the free jet in the plane of the undisturbed bed. With increasing relative seepage velocity,

$$
\frac{u_{f 0}}{\sqrt{p_{s} / \varrho}} \sim \frac{k_{f}}{b g} \sqrt{p_{s} / \varrho}
$$

more and more energy is being dissipated in the sediment bed without any effect on the erosion. This finally leads to the jet injection configuration, in which almost the entire jet energy is dissipated in the seepage flow.

For a given grain size, the erosion process in uniquely dependent upon the geometrical and flow parameters at the beginning of erosion (horizontal bed). Therefore, the erosion process can be described as a function of the pressure distribution of the impinging jet at a horizontal bed. The actual pressure distribution at the beginning of the erosion is defined by the pressure field for an impervious rough bed and by the permeability of the bed. The pressure distribution at the bed is related to the fictitions centerline velocity $u_{m, l}$, which is a function of the nozzle velocity $u_{0}$ and the distance parameter $l_{0} / d_{0}$, whereas the permeability can be expressed by the grain Reynolds number $R e_{s}$. Using $u_{m, l}$ in equation (1) the erosion process can be described as a function of $R e_{s}$ and the velocity ratio

$$
k_{0} \equiv \frac{p_{s}}{\frac{\varrho}{2} w^{2}} \propto \frac{u_{m, l}^{2}}{w^{2}}
$$

where $k_{0}$ is defined as the pressure parameter.

If the pressure parameter $k_{0}$ at the beginning of erosion does not exceed a certain limiting value $\left(k_{0} \leqq 0.025, R e_{s}=140\right)$, then for the entire erosion process, the scour form $I$ will form, which is shown in Fig. 6 . The similarity profile $I$ is characterized by the fact that the deflected jet is attached to the bed along the entire erosion zone. Only at the edge of the scour hole, at a distance $\left(r=r_{0}\right)$, 

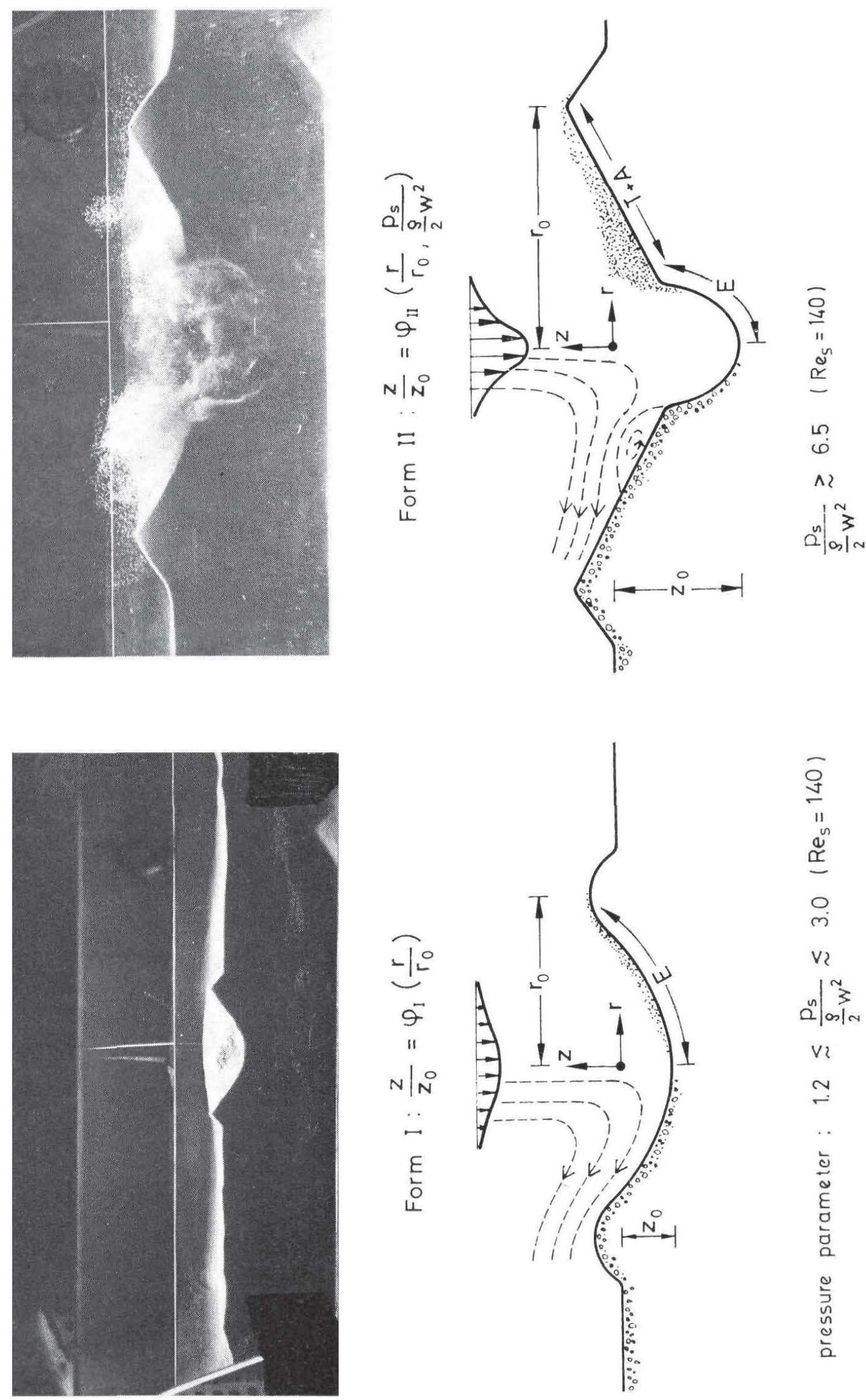

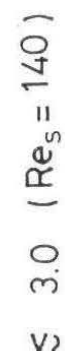

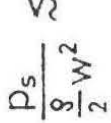

V?

$\stackrel{\sim}{\sim}$

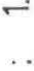

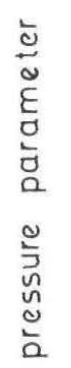

Similarity profiles of the scour hole.

Fig. 6.

Profils de similitude de la fosse d'affouillements. 
separation occurs due to the bed deformation, which however has no influence on the erosion. The bed material is put in motion in the entire deflection zone and is transported radially outward as bedload. The scour radius $r_{0}$ as the maximum transport distance is independent of time and governed exclusively by the distribution of the bed shear stress. However, the maximum scouring depth $z_{0}$ increases both with the pressure parameter and with the erosion time, and finally approaches an asymptotic limiting value.

Scour form II (see Fig. 6) is characterized by a pronounced bed deformation in the center of the jet and by an outer region with a straight slope up to the edge of the scour hole, which is determined by the inner angle of friction of the bed material. Due to the shape of the bed profile, flow separation occurs at the edge of the inner region. Under the given flow conditions, the bed material is eroded exclusively in the inner region, whereas beyond the separation point it is transported in suspension by the separated wall jet radially outward, and finally deposited. The simi-
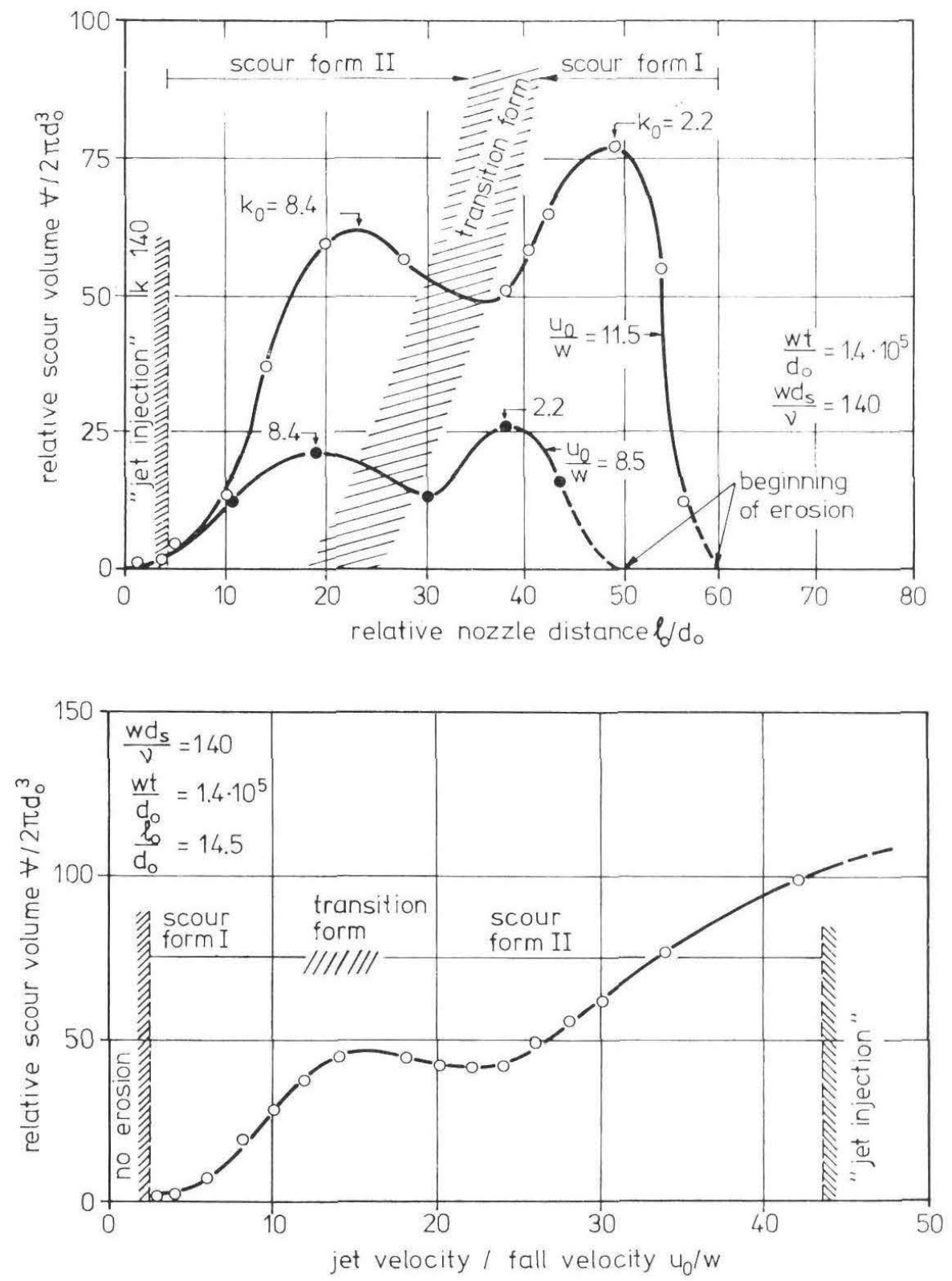

Effect of nozzle distance and jet velocity on scour volume.
Fig. 7. Influence de la distance de la buse et de la vitesse du jet sur le volume d'affouillement. 
larity profile II is a time-independent, dynamically stable configuration, which is a function of the pressure parameter $k_{0}$. With increasing values of $k_{0}$, the depth in the center of the scour hole is increased. For extreme values of the pressure parameter, the erosion is finally replaced by an injection flow, in which the scour shape II is deformed into an extremely deep hole in the jet center.

A jet with a given exit velocity $u_{0}$ and nozzle diameter $d_{0}$ shows an erosion capacity (scour volume $\forall$ for a given erosion duration) which is strongly dependent on the nozzle distance $l_{0}$ from the bed, as can be seen from the relationship between the relative scour volume and the distance parameter in Fig. 7. The maximum erosion capacity is always obtained at large nozzle distances, where the pressure parameter reaches a value of about 2.2, and no separation of the deflected jet is found. With decreasing nozzle distance, stronger pressure gradients in the deflection region yield a stronger jet deflection, and a larger portion of the energy is dissipated into the seepage flow, so that the erosion capacity is decreasing rapidly after showing a second relative maximum at $k_{0} \approx 8.4$.

A change in the jet velocity causes a change in the stagnation pressure, but no change in the width of the pressure field at the bed. An increase of the jet velocity, therefore, increases the erosion potential of the jet, which reflects in both scouring phases in an increase of the erosion rate (Fig. 7). In the intermediate velocity range ( $u_{0} / w$ from 14 to 24$)$, one finds a pronounced deformation of the bed, which causes an increased energy dissipation and a decrease of the erosion efficiency, which is defined as the jet energy imput as related to the work due to the transportation of bed material. In this region the erosion capacity remains therefore practically constant inspite of the increased jet power. Only a further increase of the jet velocity $\left(u_{0} / w>25\right)$ can yield a further increase of the erosion capacity.

The experimental investigations of the flow field and the erosion capacity of an impinging jet have shown that there is a strong feedback between flow and erosion. One can talk about jet erosion for pressure values $k_{0}$ in the range from about 1.2 up to about 140 . The larger the value of the pressure parameter, the earlier one reaches a deflection angle of more than $90^{\circ}$ and, thus, the scour form II. With increasing pressure parameter, the deflection angle of the jet increases up to values of $180^{\circ}$ (see Fig. 6). The angle of the deflected flow thus becomes more and more unfavorable, and a large portion of the eroded material is entrained directly again into the downward jet and thus does not contribute to the scouring rate. Only a minor part of the eroded material reaches the radial transport flow and is transported towards the edge of the scour hole. The material deposited on the inner flanks of the scour hole is sliding gradually towards the erosion center and is there picked up again by the flow (positive feedback). All grains, which have passed a control section at the distance $r=r_{0}$ contribute to the erosion process and thus are eliminated from the internal flow; they cause a deepening of the center of the scour hole and thus a decrease of the shear stresses at the bed (negative feedback). When the scour hole has reached similarity conditions, then there exists a dynamic balance between flow and bed form, in which the transport capacity of the radially deflected flow shows a constant ratio to the erosion capacity in the center. The scour hole increases with time while maintaining a constant scour shape and flow configuration, until finally, after extremely long erosion times, an asymptotic value is reached in deviation from the logarithmic time law. This asymptotic value, however, could not be verified experimentally because of the required extreme duration of such an experiment. 


\section{Pulsation effects on the flow field}

Velocity pulsations which are superimposed on the mean exit velocity at the nozzle have an influence on the flow field in all regions. Investigations of pulsating free jets by FAVRE-MARINET [9], Remke [10] and Olivari [11] show that pulsating jets exhibit a larger spreading angle and at the same time a more rapid decrease of the axial velocity, and that they attain similarity of the mean velocity profiles after comparatively small nozzle distances. However, the available data do not allow to establish a quantitative relationship between the observed effects and the pulsation parameters.

From the present experimental study only those results which are relevant for the jet erosion behavior will be presented, whereas the reader is referred to reference [8] for more detailed information. For evaluation of the experimental results, comparisons between steady and pulsating jets were made on the basis of equal mean momentum flux at the nozzle. The results of these investigations can be summarized as follows: Above a certain lower limit of the Strouhal number, the wall pressure at the stagnation point is decreasing, whereas the pressure field becomes comparatively wider. This effect is becoming more pronounced with increasing frequency (Fig. 8).
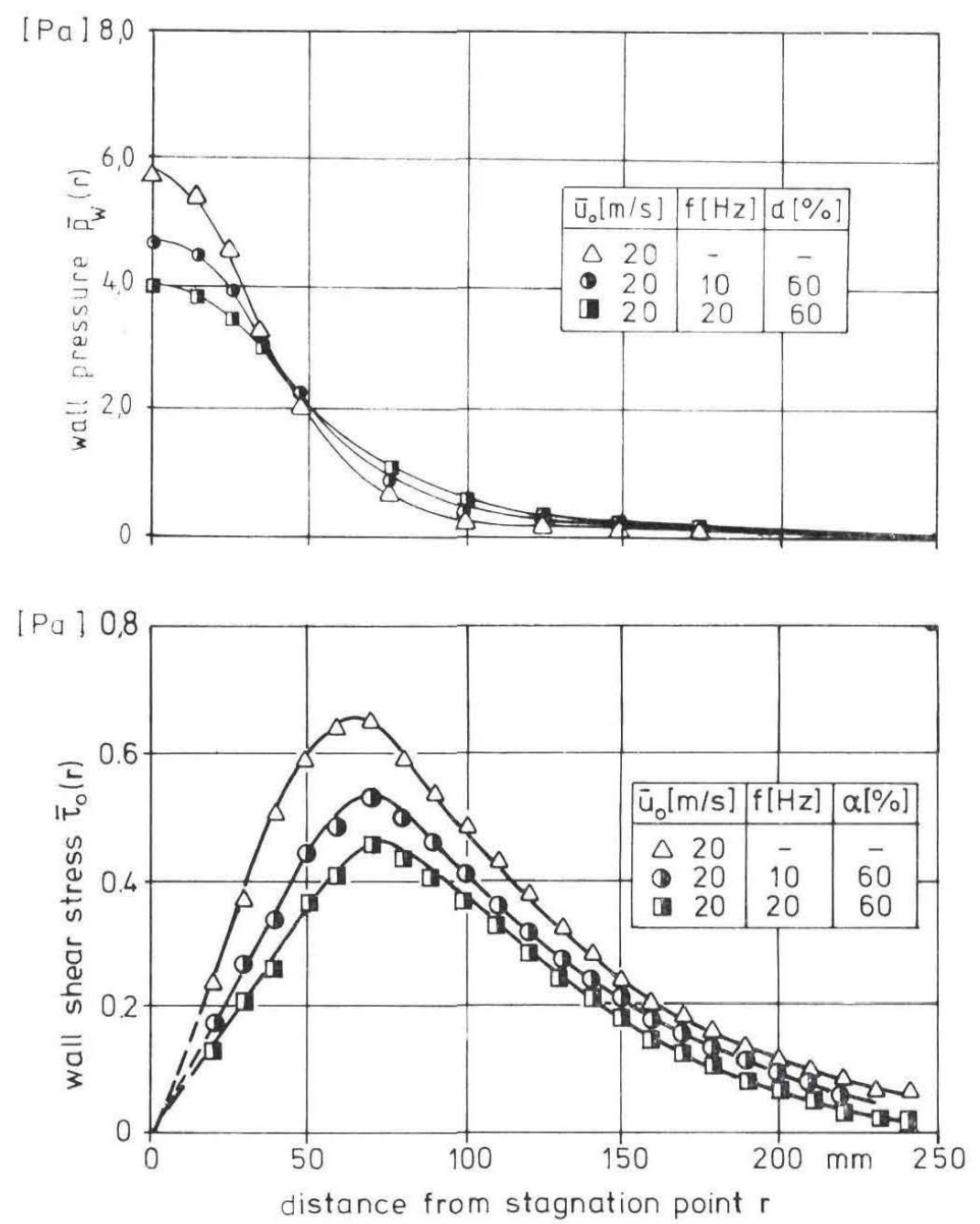

Influence of pulsation frequency on wall pressure and wall shear stress.
Fig. 8. Influence de la fréquence des pulsations sur la pression et la contrainte de cisaillement pariétales. 
The effect of the pulsation amplitude on the other hand, is of secondary importance. The pressure distribution for a pulsation jet can be described in dimensionless form by

$$
\frac{\bar{p}_{w \text { pulsating }}}{p_{w \text { steady }}}=1-60 \cdot S r^{1 \cdot 5} \cdot \exp \left[-0,0017 \cdot \operatorname{Sr}\left(r / l_{0}\right)^{2}\right]
$$

Correspondingly, the mean wall shear stresses exhibit a similar trend for Strouhal numbers above a certain lower limit, with the wall shear stress in the deflection region and in the initial part of the wall jet region decreasing with increasing Strouhal number. At large distances from the stagnation point, the values of the shear stress show no distinction for steady and pulsating jets (Fig. 8). Here also, the pulsation amplitude is of secondary importance. The dependence of the shear stress distribution in the deflection region and in the initial part of the wall-jet region upon the pulsation parameters can be described by the following equation:

$$
\frac{\bar{\tau}_{0 \text { pulsating }}}{\tau_{0 \text { steady }}}=\left(1-3.75 \cdot S r \cdot{ }^{42} \alpha^{\cdot 15} \cdot \exp \left[-7.46 r / l_{0}\right]\right)
$$

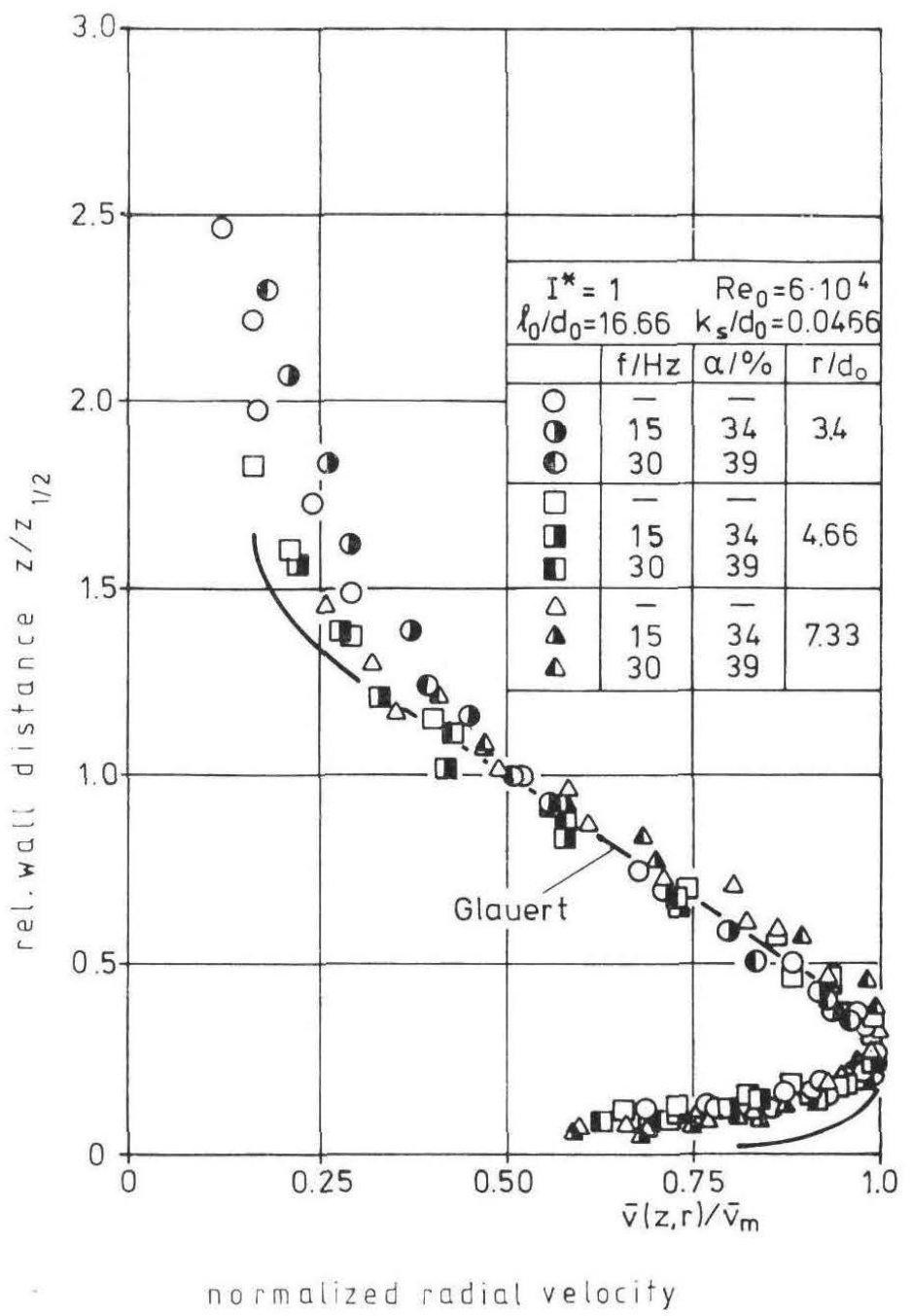

Similarity profiles of time averaged velocity within wall jet region.
Fig. 9. $\quad$ Profils de similitude de la vitesse moyenne dans le temps à l'intérieur de la zone du jet de paroi. 
The wall shear stress should be expected to depend on the Reynolds number $R e_{0}$. However, for the Reynolds number range investigated here no influence has been detected [8]. The velocity profiles in the wall-jet region show similarity behavior for both continuous and pulsating jets (Fig. 9).

Unlike the mean velocity behavior, the turbulence structure shows a significant difference. In the flow field of the pulsating jet, hot-wire measurements have been performed and analyzed by means of auto- and cross-correlation. By correlation techniques, periodic parts have been

$$
R_{\varphi}^{*}=\frac{\overline{V\left(r_{m}, 2 k_{s}, 0 ; t\right) \cdot V\left(r_{m}, 2 k_{s}, \varphi ; t\right)}}{\overline{V^{2}\left(r m, 2 k_{s}, 0 ; t\right)}}
$$
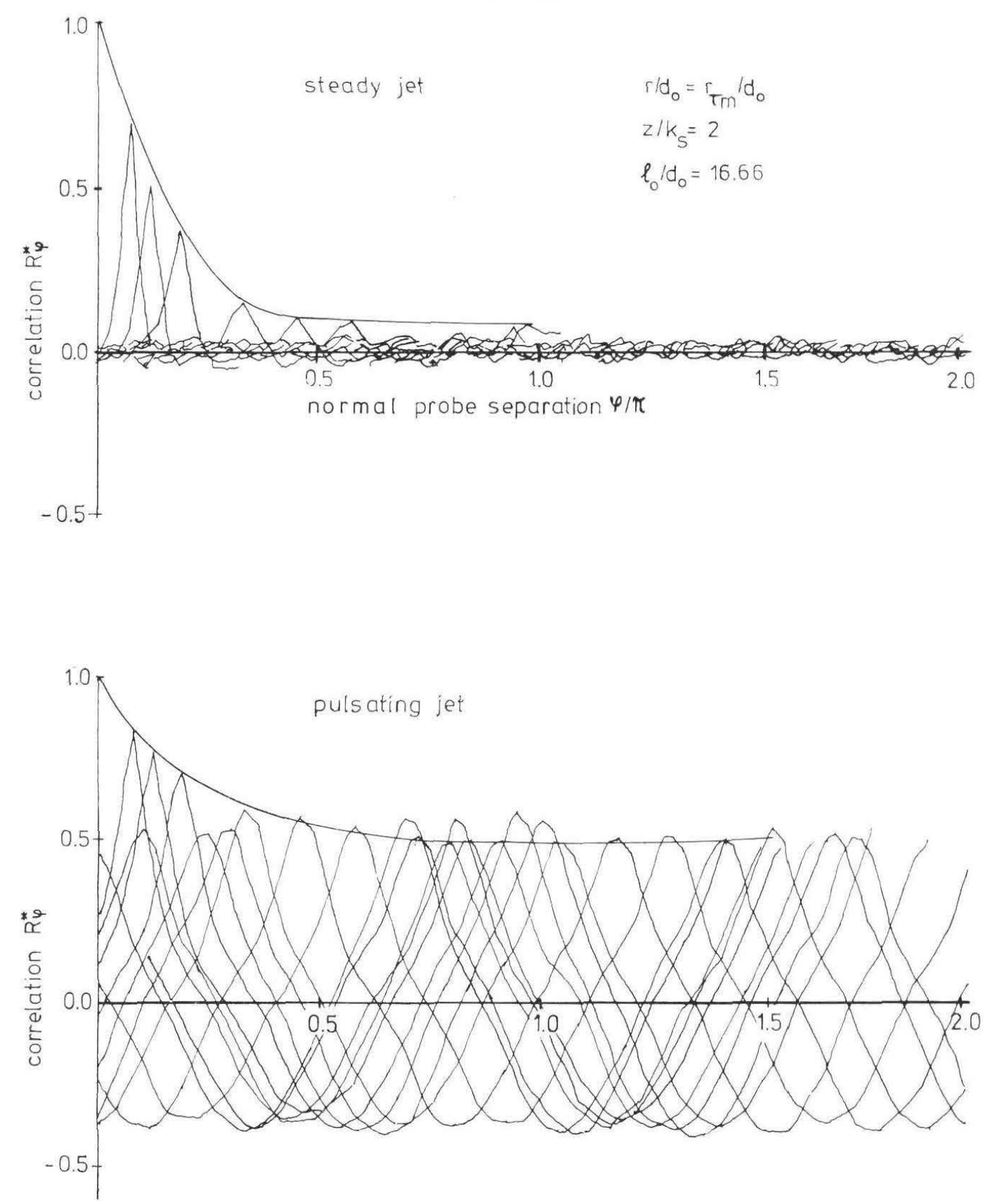

Azimuthal crosscorrelation of radial velocity fluctuation without and with pulsation.
Fig. 10. Corrélation azimutale réciproque des fluctuations des vitesses radiales, avec et sans pulsations. 
separated from the stochastic parts of the signal in order to quantify the mutual interrelationship of periodic and stochastic components. Measurements have been taken both in the boundary layer near the wall and in the free shear zone of the wall jet. One probe was mounted at $z=2 k_{s}$, whereas the second probe was traversed at the same elevation around the circumference. Fig. 10 shows the normalized two - point correlations of the radial fluctuations at the beginning of the wall-jet region, that is at the point of maximum wall shear stress. For a steady impinging jet, the two-point correlation decreases rapidly with increasing separation angle of the probes, which means that the instantaneous fluctuating components in the radial outward direction, which are mainly responsible for the erosion and the transport of bed material, are not particularly well correlated. In contrast, the pulsating jet shows well-correlated fluctuating components in the outward direction around the entire circumference.

The separation of the fluctuating components into periodic and stochastic parts showed for the radial fluctuations in the boundary layer no interference of these components, which means that the turbulence structure within the wall boundary layer is not changed by the pulsation. In the free-shear layer of the wall jet, on the other hand, the velocity pulsations interfere primarily with those turbulence elements (eddies) which have a frequency corresponding to the pulsation frequency. By this process, the periodic motion feeds energy into these large eddies and thus prolongs their duration of existence. Intensity measurements of the total fluctuations in the freeshear zone show that the pulsating jet exhibits an increased total fluctuation (Fig. 11). The respective contribution of periodic and stochastic parts to the total fluctuation has been determined and is given in [8].

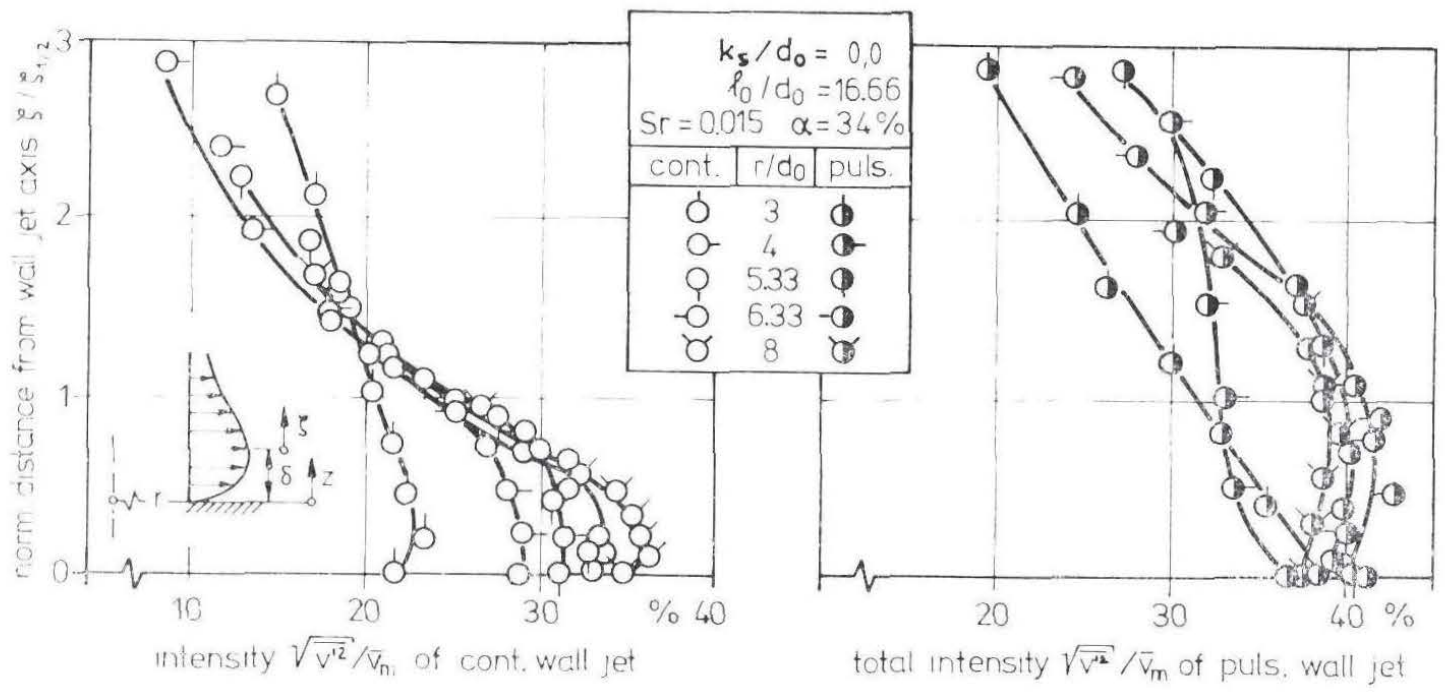

Comparison of axial fluctuation intensities in the outer shear layer.
Fig. 11 .
Confrontation des intensités des fluctuations axiales dans la couche de cisaillement extéricure.

\section{Pulsation effects on the scouring process}

Knowledge of the influence of velocity pulsations upon the flow field of an impinging jet on an impermeable wall allows some conclusions concerning the influence of the pulsation upon the erosion process. Since the pulsation leads to a decrease of the velocity on the jet axis, and thus to a wider pressure field, the deflection region is increased in width. At the same time, the induced seepage velocity in the sediment bed is diminished because the pressure gradient is smaller, so that an increased erosion action can be expected. 
The pulsation does not only influence the erosion because of the changes of the mean flow field, but also by the changes of the turbulence characteristics. The strong correlation of the fluctuating components is of particular importance both for the instantaneously increased attack on the grain bed and for a more efficient transport of the particles in suspension from the erosion zone to the outer edge of the scour hole. In order to set a grain in motion by fluid dynamic forces, the driving dynamic force must be larger than the retaining friction force and the retarding inertial force of the grain including the surrounding fluid (added mass) and the component of the gravitational force of the submerged grain. In order to retain the grain in motion and not let it slide back into its initial position, but transport it at least by rolling over the neighboring grain, the fluid dynamic force must be acting for a certain minimum duration time, which depends upon the turbulent fluctuations. Since the resulting direction of transport is given by the mean radial flow, the flow shows a greater efficiency when the direction of the resulting fluid dynamic force coincides with the radial direction. The stronger the correlation of the force fluctuations in the direction of the transport is along a circular circumference, the more turbulent energy can be supplied for erosion and transport. Since the driving fluid dynamic force is influenced by the turbulent fluctuations, the correlation of the radial velocity fluctuations over the circumference gives an indication of the orderly attack of the fluctuating flow components. As the pulsating jet has considerably higher correlation in the radial direction than the steady jet of equal mean momentum-or mass flux at the nozzle (Fig. 10), the forces on the grains due to turbulence are directed more strongly in the radial direction and are less random. The stronger correlation thus has the consequence that the flow is more effective with regard to erosion and transport of the grains.

Since pulsations at the nozzle change the distribution of mean pressure and velocity profiles at the bed considerably in comparison to the steady jet, the erosion process takes place under different initial conditions. The changes of the mean velocity profiles in the free jet region corres-

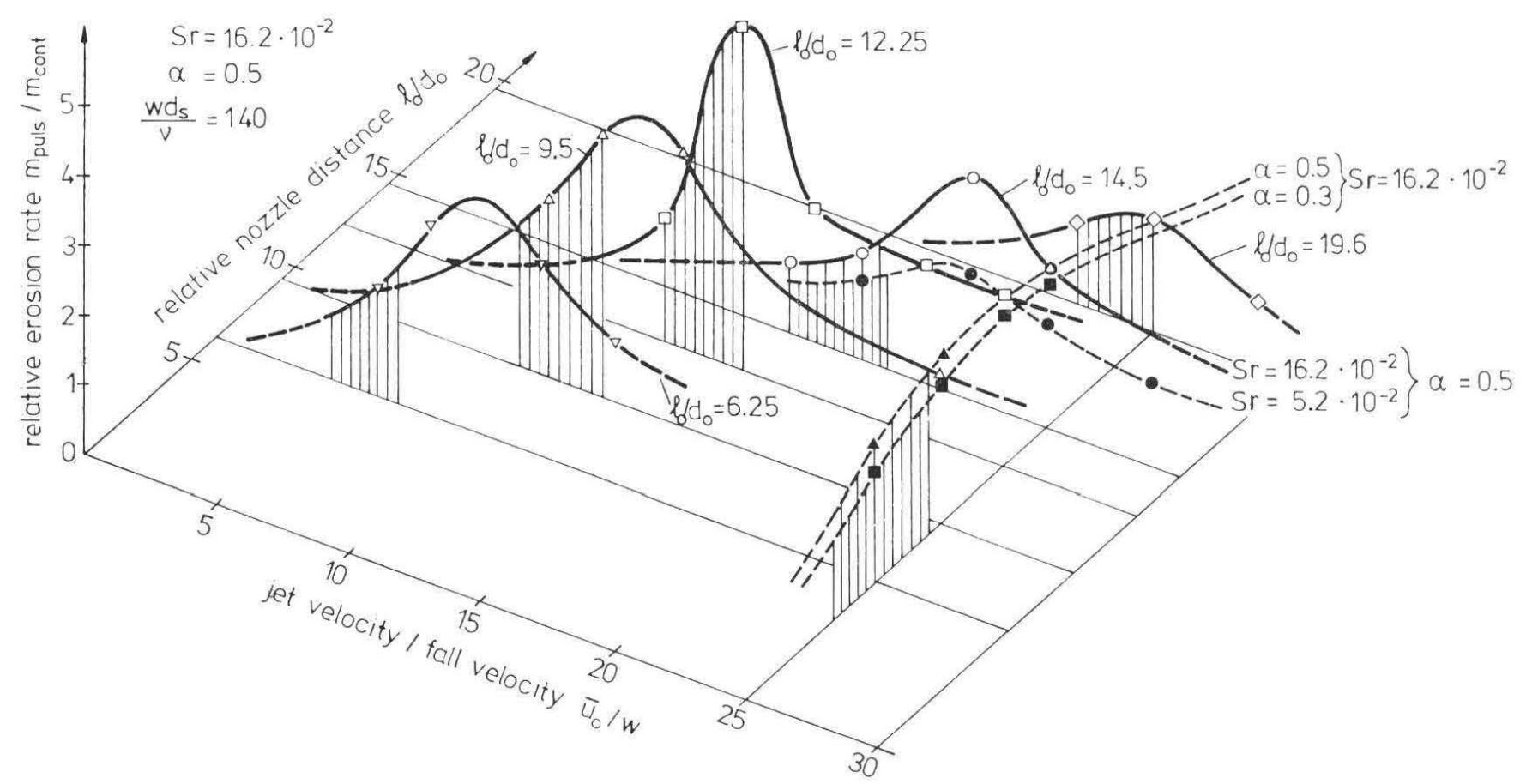

Increase of erosion rate due to pulsation depending on nozzle distance and jet velocity.
Fig. 12.
Accroissement du taux d'érosion du fait des pulsations, en fonction de la distance de la buse et de la vitesse du jet. 
pond qualitatively, to a shift of a steady jet of equal momentum flux away from the bed and thus to an increased nozzle distance. The erosion rate of a pulsating jet is increasing with increasing frequency and amplitude of the pulsation. It is increased both in phase I and phase II of the scouring process. Since phase II is the phase of main importance for practical applications, and since it can be described sufficiently accurately, this phase will serve as a basis of comparison for the erosion capacity of both types of jets.

For given pulsation parameters, Fig. 12 shows the ratio of the erosion rates for pulsating and steady jets in scouring phase II for various values of the distance - and velocity parameter. It can be shown that the influence of the pulsation is a maximum when the change in flow conditions leads to a shift from scour form II to form I. The absolute maximum increase of the erosion rate due to pulsation of about 5 times the steady state erosion rate has been observed for quartz sand at a distance parameter $l_{0} / d_{0}$ of around 12 and a velocity parameter $\bar{u}_{0} / w$ of about 16 which corresponds to $k_{0}=140$. Under these conditions, the erosion process is increased substantially in comparison to a steady jet of the same mean momentum flux.

\section{Conclusions}

The mean and fluctuating components of the flow field of vertical submerged jets impinging on a horizontal rough wall have been measured, and the time-development of scour holes due to submerged jets impinging on sand beds of uniform grain size has been studied experimentally. Particular attention has been paid to the quantification of pulsation effects upon the flow field and the scouring process. The results allow quantitative assessment of the various parameters upon the scouring process for steady and pulsating jets. In particular, the following general conclusions can be derived from the study:

- The scouring process has a logarithmic time dependence.

- The erosion capacity of a jet depends upon its momentum flux, the nozzle distance from the bed, and the properties of the bed material.

- Depending on the magnitude of the pressure parameter $k_{0}=p_{s} /(\varrho / 2) w^{2}$, different scour forms may be generated. For small values of $k_{0}\left(1.2 \approx k_{0}<3\right)$ one obtains form I, for larger values of $k_{0}\left(6.5 \approx k_{0}<140\right)$ the form II, whereas very large values of $k_{0}$ lead to injection flow.

- Scour form I shows a shallow profile, in which the wall jet is attached up to the edge of the scour hole. Erosion takes place mainly in the form of bedload transport.

- Scour form II exhibits a strong deformation in the inner region, where erosion takes place, and straight flanks in the outer region of the scour hole, in which transport in suspension and partial deposition take place.

- Periodic pulsation of the jet can cause a significant increase of the erosion capacity. This is due to the following factors:

- more favorable erosion- and transport conditions in the deflected jet due to a diminished pressure gradient along the bed;

- smaller energy loss into the seepage flow on account of the reduction of the pressure gradient, which reduces the seepage flow;

- better efficiency of the turbulent transport because of the pronounced radial correlation of the radial velocity components around the circumference. 
1. Glauert, M. B., The wall jet, Journal of Fluid Mechanics, 1, (1956), pp. 625-643.

2. Bradshaw, P. and E. M. Love, The normal impingement of a circular air jet on a flat surface, Acronautical research council reports and memorandum No. 3205, 1959.

3. Poreh, M. et al., Investigation of a turbulent radial wall jet, Journal of Applied Mechanics, (1967), pp. 457463.

4. Rajaratnam, N., Turbulent Jets, Elsevier Scientific Publishing Co., 1976.

5. Sandborn, V. A. and J. L. Chao, Evaluation of the momentum equation for a turbulent wall jet, Journal of Fluid Mechanics, Vol. 26, (1966), 4 pp. 819-828.

6. LAM LAU, Flow characteristics of wall-jets on smooth, rough and porous walls, Department of Mechanical Engineering University of Toronto, Canada, Masters Thesis, 1963.

7. Jayatilleke, C. L. V., The influence of Prandtl number and surface roughness on the resistance of the laminar sublayer to momentum and heat transfer, Progress in Heat and Mass Transfer, 1, (1969), pp. $193-329$.

8. Leister, P., Momentum and mass transfer in impinging, pulsating jets, University of Karlsruhe, Dissertation, February 1977 (in German).

9. Favre-Marinet, M. et al., Jets instationaires, Etude No. 2, Structure Des Jets Pulsants, Université Grenoble, Octobre 1971 et Juin 1972.

10. RemKe, K., Untersuchungen an pulsierenden turbulenten Freistrahlen, Mitteilungen des Instituts für angewandte Mathematik und Mechanik, Universität Berlin (DDR), 1972.

11. Olivari, D., Analysis of an axisymmetrical turbulent pulsating jet, Von Kharman Institute for Fluid Dynamics, Technical Note 104, (1974).

12. Poreh, M. and E. Hefez, Initial scour and sediment motion due to an impinging submerged jet, Proc. IAHR Conference, Fort Collins, Vol. 3, 1967.

13. Rouse, H., Criteria for Similarity in the Transportation of Sediment, Proc., ASCE Hydr. Conf., Pasadena, 1942.

14. Altinbilek, H. and S. Okyay, Localized Scour in a Horizontal Sand Bed under Vertical Jets, Proc., IAHR Conference, Istanbul, 1973.

15. Laursen, E., Observation on the Nature of Scour, ASCE, Proc. 5th Hydr. Conf., No. 426, June 1952.

16. O'Loughlin, E. M. et al., Scale Effects in Hydraulic Model Tests of Rock Protected Structures, IAHR Report, Inst. of Hydr. Res., February 1970.

17. Westrich, B., Influence of Seepage Flow and Velocity Pulsations in Jet-Erosion, EUROMECH 48, Kopenhagen, 1974.

\section{Notations}

A Constant

$d_{0} \quad$ Nozzle diameter

$d_{s} \quad$ Mean grain diameter

$f \quad$ Pulsation frequency

$k_{0} \quad$ Pressure parameter

$k_{f}$ Darcy permeability

$k_{s} \quad$ Equivalent sandroughness

$l_{0} \quad$ Nozzle to wall distance

$M_{0}$ Momentum flux

$p_{w} \quad$ Wall pressure

$p_{s} \quad$ Stagnation pressure, $p_{s}=\bar{p}_{w}(r=0)$

$r_{0} \quad$ Nominal scour radius

$R e_{0}$ Nozzle Reynolds number $=u_{0} \cdot d_{0} / v$

$R e_{s}$ Grain Reynolds number $=w \cdot d_{s} / v$

$r \quad$ Radial coordinate

$S r \quad$ Strouhal number $=f \cdot d_{0} / u_{0}$

$t$ scouring time $u, v$ Velocity in $x$ - and $r$-direction

$u_{f} \quad$ Seepage velocity

$\forall \quad$ Scour volume

$z \quad$ Distance from wall

$\alpha \quad$ Amplitude of pulsation

$\delta \quad$ Thickness of boundary layer

$\varphi \quad$ Azimuthal angle

$v \quad$ Kinematic viscosity

$\varrho \quad$ Density

$\tau \quad$ Wall shear stress

$\propto$ proportional

subscripts:

$m, l$ maximum value at distance $l$

$f \quad$ Darcy

o Nozzle

$s \quad$ sand 